\title{
Plasma tumour necrosis factor alpha in cystic fibrosis
}

\author{
D Norman, J S Elborn, S M Cordon, R J Rayner, M S Wiseman, E J Hiller, D J Shale
}

\begin{abstract}
Plasma tumour necrosis factor alpha $(\alpha)$ concentration is increased in acute Gram negative sepsis, but the effect of chronic infection on plasma concentrations is unknown. A study was carried out in patients with cystic fibrosis to determine the effect of chronic lung infection with Pseudomonas aeruginosa on the plasma concentration of tumour necrosis factor and two other indicators of the inflammatory response, circulating $C$ reactive protein and neutrophil elastase- $\alpha_{1}$ antiproteinase complex (elastase complex). The concentration of immunoreactive tumour necrosis factor in plasma was greater than the upper $95 \%$ confidence interval for healthy subjects $(2.6 \mathrm{U} / \mathrm{ml})$ on 129 out of 189 occasions in 14 patients observed for about a year. The increase in tumour necrosis factor was associated with increased circulating $\dot{\mathbf{C}}$ reactive protein and elastase complex. Twelve patients with an exacerbation of respiratory symptoms were studied before and after two weeks' treatment with antipseudomonal antibiotics. All three indicators of the inflammatory response fell after treatment, though median tumour necrosis factor $(4.8 \mathrm{U} / \mathrm{ml})$ and elastase complex $(0.41 \mu \mathrm{g} / \mathrm{ml})$ concentrations remained above the upper limits for healthy subjects. During a period of clinical stability plasma tumour necrosis factor was increased in 10 of the 12 patients, elastase complex was increased in 10 of the 12 , and $C$ reactive protein was increased in seven. Increased plasma immunoreactive tumour necrosis factor was a feature of the near continuous inflammatory response to chronic $P$ aeruginosa infection in cystic fibrosis and may be a factor contributing to the progressive lung destruction seen in this disease.
\end{abstract}

Tumour necrosis factor alpha $(\alpha)$-cachectin is synthesised and secreted by monocytes and macrophages in response to bacterial endotoxaemia both in animals and in man. ${ }^{1-3}$ In animals tumour necrosis factor is a mediator of septic shock and multiple organ failure, and its effects may be abolished by passive immunisation with antibodies to recombinant tumour necrosis factor. ${ }^{34}$

The concentration of bioactive tumour necrosis factor in serum is increased in patients with meningococcal meningitis and septicaemia and absolute concentrations have been shown to predict survival. ${ }^{56}$ Serum concentrations of other cytokines, including interleukins 1 and 6 , were also increased and had prognostic value. ${ }^{6}$ Serum tumour necrosis factor was also increased in patients with falciparum malaria and the concentrations were related to severity as assessed clinically. ${ }^{7}$ In all these conditions the increase in tumour necrosis factor was associated with an acute infective disorder and a high mortality rate, but tumour necrosis factor may also be increased in chronic parasitic conditions. ${ }^{8}$

The lungs of patients with cystic fibrosis are infected in the later stages with Pseudomonas aeruginosa, and the acquisition of this organism is a major determinant of survival. ${ }^{10}$ Concentrations of circulating tumour necrosis factor may be increased in such patients but its relation to the host inflammatory response and lung injury is unknown."

To determine the effect of chronic infection with $P$ aeruginosa on circulating tumour necrosis factor and its relation to other indicators of the inflammatory response we measured immunoreactive tumour necrosis factor in plasma from patients with cystic fibrosis. Changes in tumour necrosis factor concentrations were compared with two other indicators of the inflammatory response and lung function over 12-14 months. The effect of antibiotic treatment on circulating concentrations of tumour necrosis factor and other inflammatory markers was determined at the time of deteriorating respiratory function.

\section{Methods}

PATIENTS

Fourteen patients (aged 14-22 years) were studied prospectively. Cystic fibrosis was confirmed on the basis of clinical history and a positive sweat test result in infancy $\left(\mathrm{Na}^{+}\right.$and $\mathrm{Cl}^{-}$concentration $>60 \mathrm{mmol} / \mathrm{l}$ ). All had chronic purulent sputum production, 13 were chronically infected with $P$ aeruginosa, and the remaining patient progressed from intermittent to chronic infection during the study. Venous blood was taken at intervals of about two months over 12-14 months and more frequently when a symptomatic respiratory deterioration occurred and antibiotic treatment was started. Blood was collected into disodium EDTA ( $3.4 \mathrm{mmol} / 1$ final concentration) and 
kept on ice until separation. A serum sample was also obtained. Separation was completed within 30 minutes of collection and plasma and serum were stored at $-70^{\circ} \mathrm{C}$ until they were assayed for tumour necrosis factor, neutrophil elastase- $\alpha_{1}$ antiproteinase complex (elastase complex), and $C$ reactive protein. The treatment of respiratory exacerbations was independent of these measurements, which were all made after completion of the 12-14 month study period. Antibiotic treatment was initiated when increased respiratory symptoms or signs occurred with deterioration in lung function. The choice of antibiotic was based on standard bacterial sensitivity testing and the supervising physician's preference.

The patient's clinical data for the whole period of observation were subsequently reviewed by an independent observer, who, unaware of the data on inflammatory markers, identified the most definite episode of pulmonary exacerbation. The criteria for an exacerbation were: an increase in sputum volume and purulence; a reduction of forced expiratory volume in one second $\left(\mathrm{FEV}_{1}\right)$ of $15 \%$ or more from a previously recorded value when the patient was clinically stable in the preceding year; institution of antibiotic treatment. A period of clinical stability was identified, even though the patient was still infected, as a time of no antibiotic treatment, respiratory symptoms at a baseline level for that patient, and an $\mathrm{FEV}_{1}$ of less than $15 \%$ below the best recorded value for the year.

A group of apparently non-infected, healthy volunteers $(n=32)$, their ages matched to within five years of the ages of the patients' with cystic fibrosis, were used to establish a normal range for circulating inflammatory markers.

\section{ASSAYS}

Tumour necrosis factor

Ninety six well microtitre plates (Immunlon IV irradiated, Dynatec Laboratories Ltd) were coated with monoclonal antibody to tumour necrosis factor $(1: 1000)$ in bicarbonate buffer (pH 9.6) at $4^{\circ} \mathrm{C}$ overnight. Assay plates were blocked with $50 \mu \mathrm{l} /$ well of $2 \%$ bovine serum albumin in phosphate buffered saline (PBS, pH $7 \cdot 4$ ) for one hour at $37^{\circ} \mathrm{C}$. Assay plates were then washed with PBS buffer containing $0.01 \%$ Tween 20 . Three rapid washes were followed by three three-minute soaks with the same buffer. Standard tumour necrosis factor (interim standard) or a sample (50 $\mu \mathrm{l} /$ well) diluted in PBS containing $0.1 \%$ gelatin and $0.05 \%$ Tween 20 was added, incubated at $4^{\circ} \mathrm{C}$ overnight, and washed as before. After the washing $50 \mu \mathrm{l} /$ well of rabbit anti-tumour necrosis factor (1:500 in sample buffer; Genzyme Ltd) was allowed to act for two hours at $37^{\circ} \mathrm{C}$. Plates were washed as previously and $50 \mu \mathrm{l} /$ well of biotinylated anti-rabbit antibody (1:1000 in sample buffer; Sigma Chemical Company Ltd) was added for one hour at $37^{\circ} \mathrm{C}$. Plates were washed as before and avidinperoxidase complex, $50 \mu \mathrm{l} /$ well $(1: 1000$ in borate saline buffer, $\mathrm{pH} 8.6$ ), was added and incubated at room temperature for one hour.
Plates were washed four times in borate saline buffer with a four minute soak during each wash period. Peroxidase substrate mixture, 100 $\mu \mathrm{l} /$ well, was allowed to act for 30 minutes at room temperature. This reaction was stopped by the addition of $3 \mathrm{M}$ sodium hydroxide, $50 \mu \mathrm{l} /$ well. Absorbance was read at $455.5 \mathrm{~nm}$.

Each assay included eight buffer containing (zero tumour necrosis factor) wells per plate and a tumour necrosis factor standard curve from 2.5 to $80 \mathrm{U} / \mathrm{ml}$, each concentration in duplicate. Plasma samples were assayed at 1:2 dilution in duplicate and quality controls were included with each assay. The tumour necrosis factor concentration of specimens was calculated from a regression line derived from the standard curve. Sensitivity, defined as the mean plus two standard deviations of the absorbance of the eight buffer containing wells, was $1.13 \mathrm{U} / \mathrm{ml}$ on the basis of 20 assays.

\section{Other assays}

$C$ reactive protein and elastase complex were determined by enzyme linked immunosorbent assays developed in our laboratory. ${ }^{1213}$ The C reactive protein assay has a sensitivity of $7 \cdot 3 \mathrm{ng} /$ $\mathrm{ml}$ and intra-assay and interassay coefficients of variation of $4.4 \%$ and $9.2 \%$ respectively in our laboratory. Elastase complex was detected in an assay dependent on capture of neutrophil elastase- $\alpha_{1}$ antiproteinase complex by an antibody to human neutrophil elastase and detection with a biotinylated antibody to human $\alpha_{1}$ antiproteinase. Intra-assay and interassay coefficients of variation are $6.7 \%$ and $12 \%$. $^{13}$

\section{STATISTICAL METHODS}

Owing to the small number of subjects $\mathrm{FEV}_{1}$, $C$ reactive protein, tumour necrosis factor, and elastase complex before and after antibiotic treatment were compared by the paired Wilcoxon test, and results are expressed as the median change and $95 \%$ confidence interval (CI) of that change. ${ }^{14}$

\section{Results}

HEALTHY SUBJECTS

For the 32 healthy subjects the mean plasma tumour necrosis factor concentration was 1.6 (95\% confidence interval $0 \cdot 8-2 \cdot 6) \mathrm{U} / \mathrm{ml}$, mean elastase-complex $0.27(95 \%$ CI $0.22-0.32) \mu \mathrm{g} /$ $\mathrm{ml}$, and mean $\mathrm{C}$ reactive protein $1.28(95 \% \mathrm{CI}$ $0 \cdot 79-1 \cdot 79) \mu \mathrm{g} / \mathrm{ml}$.

\section{LONG TERM OBSERVATIONS}

Patients were studied for a median of 347 (range 109-414) days. C reactive protein, elastase complex, and tumour necrosis factor concentrations varied within and between patients during the study (fig 1). All patients had a raised tumour necrosis factor concentration on at least one occasion, though the median values for four individuals were within the range of those of the healthy subjects. Tumour necrosis factor concentrations were greater than the upper $95 \%$ CI for the healthy subjects in 129 out of 189 samples in the 14 patients with cystic fibrosis. $C$ reactive protein and elastase-complex values also varied sub- 

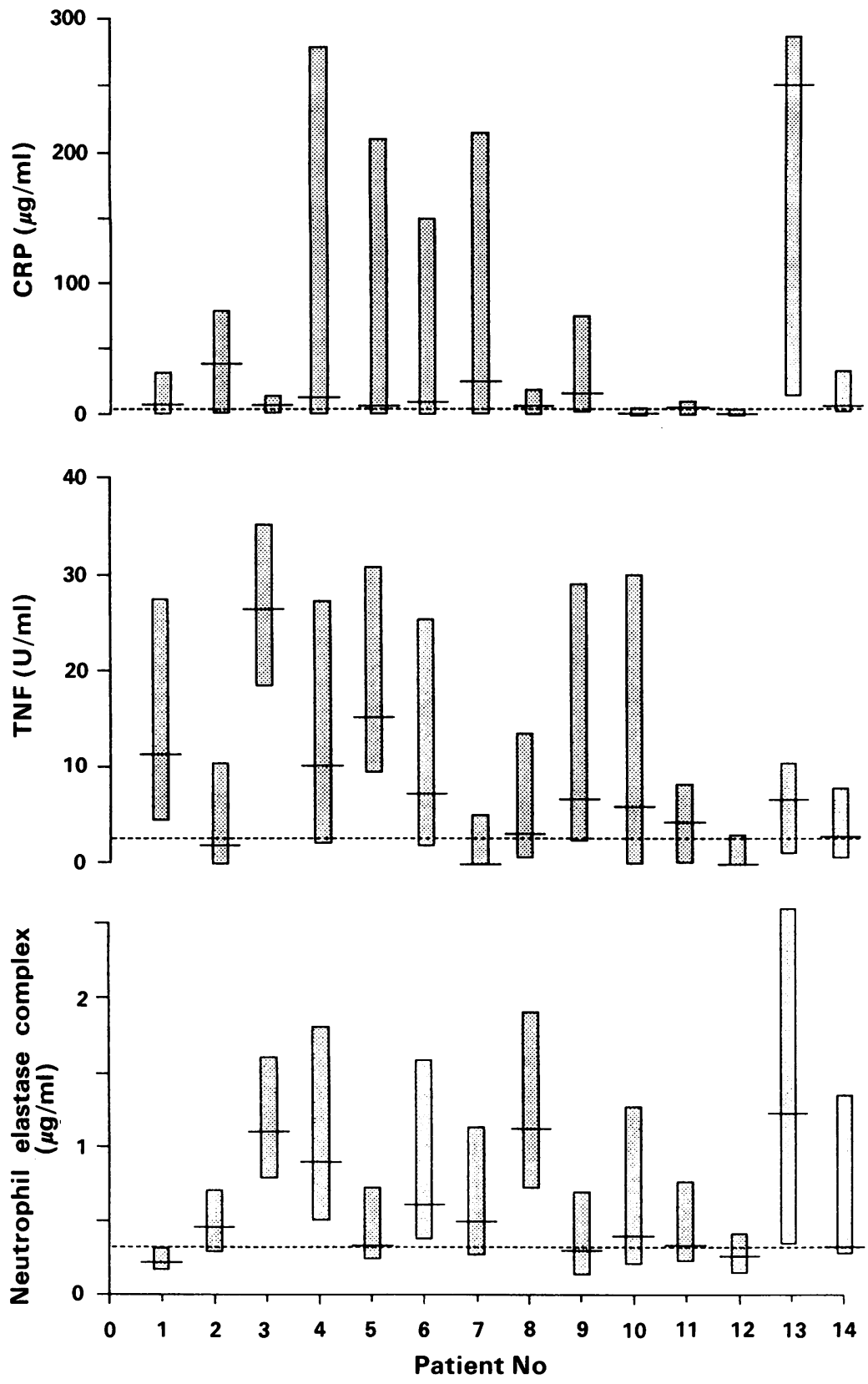

Figure $1 C$ reactive protein (CRP), elastase complex, and tumour necrosis factor ( TNF) values for 14 patients studied over 109-414 days. The hatched area indicates the range of values for each patient and the bar indicates the median value. The dotted line indicates the upper $95 \%$ confidence limit for healthy controls.

stantially within and between patients, and no direct relation was detected with tumour necrosis factor concentrations or with change in $\mathrm{FEV}_{1}$.

\section{EFFECT OF ANTIBIOTIC TREATMENT ON} INDICATORS OF THE INFLAMMATORY RESPONSE The circulating concentrations of the three inflammatory markers were further examined in 12 of the 14 patients before and after treatment of a symptomatic respiratory exacerbation. Two patients were excluded-one (patient 13 in fig 1) because no symptomatic deterioration requiring antibiotics occurred and one (patient 14 in fig 1) because of continuous antibiotic treatment during the study period of 109 days up to death. In the remaining 12 patients median concentrations of $\mathrm{C}$ reactive protein, elastase complex, and tumour necrosis factor were above the $95 \%$ CI for the healthy subjects when they were first seen after the start of a respiratory exacerbation. After two weeks' antibiotic treatment there was a significant reduction in tumour necrosis factor (median difference $-9.4 \mathrm{U} / \mathrm{ml}, 95 \%$ CI -3.6 to $-14.2 \mathrm{U} / \mathrm{ml}, \mathrm{p}=0.003), \mathrm{C}$ reactive protein $(-17 \cdot 2 \mu \mathrm{g} / \mathrm{ml}, \mathrm{CI}-6 \cdot 3$ to $-41 \cdot 7 \mu \mathrm{g} / \mathrm{ml}, \mathrm{p}=$ $0.0025)$, and elastase complex $(-0.25 \mu \mathrm{g} / \mathrm{ml}$, $\mathrm{CI}-0.16$ to $-0.50 \mu \mathrm{g} / \mathrm{ml}, \mathrm{p}=0.0025)$, and an increase in $\mathrm{FEV}_{1}(+0.381$; CI 0.18 to 0.881 , $\mathrm{p}=0.0025)$-see figures 2 and 3 . For most patients, however, only $\mathrm{C}$ reactive protein returned to within the range for healthy subjects. At a time of clinical stability, 20-133 days after treatment, most patients had $\mathrm{C}$ reactive protein, elastase-complex and tumour necrosis factor concentrations that were greater than the upper $95 \%$ confidence limit of the healthy subjects, but below the pretreatment concentrations; the $\mathrm{FEV}_{1}$ value was no different from the value after antibiotic treatment (figs 2 and 3).

\section{Discussion}

Plasma immunoreactive tumour necrosis factor was often increased in patients with cystic fibrosis and chronic $P$ aeruginosa lung infection, confirming a previous report of isolated increase in plasma tumour necrosis factor in such patients. ${ }^{11}$ Our data extend that observation and show the chronic nature of the increase in circulating tumour necrosis factor. The sustained increase in tumour necrosis factor in some patients suggests that the inflammatory response does not adapt to chronic localised infection. This is supported by the finding that elastase complex and $C$ reactive protein were also increased in most patients. The continued inflammatory process during periods of apparent clinical stability and symptomatic remission probably indicates that occult lung injury is occurring at this time. As tumour necrosis factor is a major regulator of the host inflammatory response its continuous secretion may be a factor in the lung injury associated with cystic fibrosis. ${ }^{15-17}$

High concentrations of circulating tumour necrosis factor may represent either a spillover from a localised inflammatory response in the lung or wider systemic activation of cells of the monocyte-macrophage series in response to circulating antibody-bacterial endotoxin complexes. ${ }^{18}$ Circulating tumour necrosis factor may be a factor in the systemic effects of chronic infection, such as the cachexia that characterises cystic fibrosis despite appropriate pancreatic enzyme replacement and dietary supplementation. Weight loss is often used as an indicator of deterioration and the need to treat with antibiotics, and weight gain is a feature of the response to treatment. ${ }^{19}$ Increased plasma concentrations of tumour necrosis factor may influence body weight by acting as a circulating hormone. We cannot comment directly on the bioactivity of the tumour necrosis factor detected in this study, but the polyclonal detector antibody used in the enzyme linked immunosorbent assays neutralises tumour necrosis factor bioactivity 
Figure 2 Effect of 14 days' antibiotic treatment on FEV , and serum $C$ reactive protein (CRP) in 12 patients with cystic fibrosis. Individual values and group medians are given. Values are also given for each patient during a period of clinical stability. The dotted line indicates the upper $95 \%$ confidence limit for healthy controls.
Figure 3 Effect of 14 days' antibiotic treatment on plasma tumour necrosis factor (TNF) and elastase complex in 12 patients with cystic fibrosis. Individual values and group medians are given. Values are also given for each patient during a period of clinical stability. The dotted line indicates the upper $95 \%$ confidence limit for healthy controls.

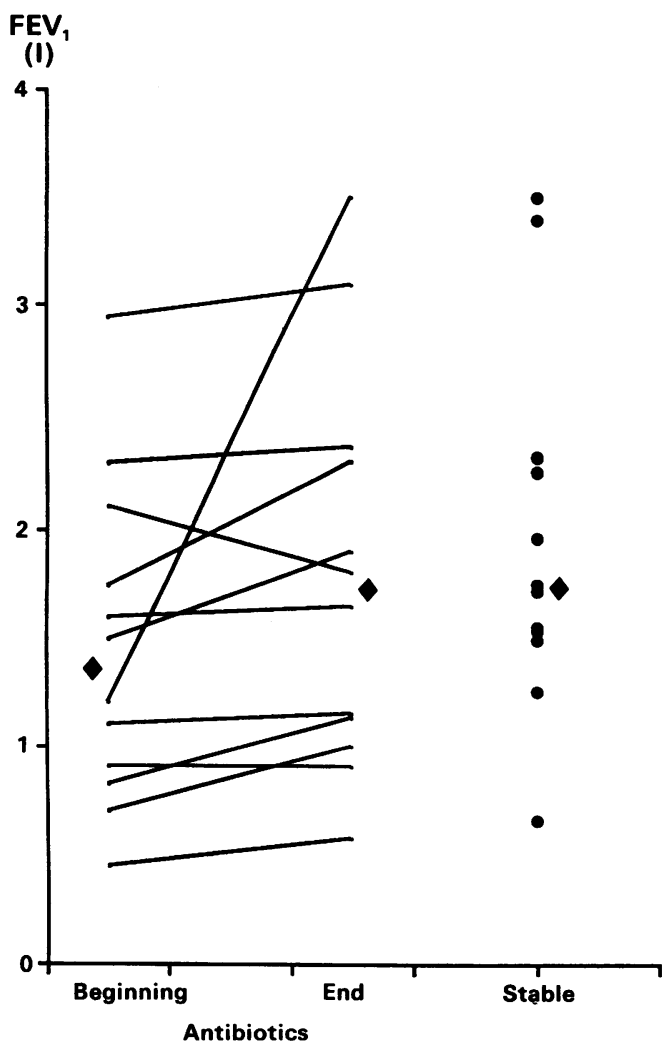

in serum from patients with cystic fibrosis in the WEHI 164 cell bioassay (Norman, unpublished data).

The reduction of plasma $\mathrm{C}$ reactive protein and elastase complex concentrations that follows antibiotic treatment confirms earlier reports ${ }^{2021}$ and the parallel change in tumour necrosis factor is in keeping with its suggested regulatory role in inflammation. Reduction in tumour necrosis factor and the secretion of other cytokines may have reduced the level of

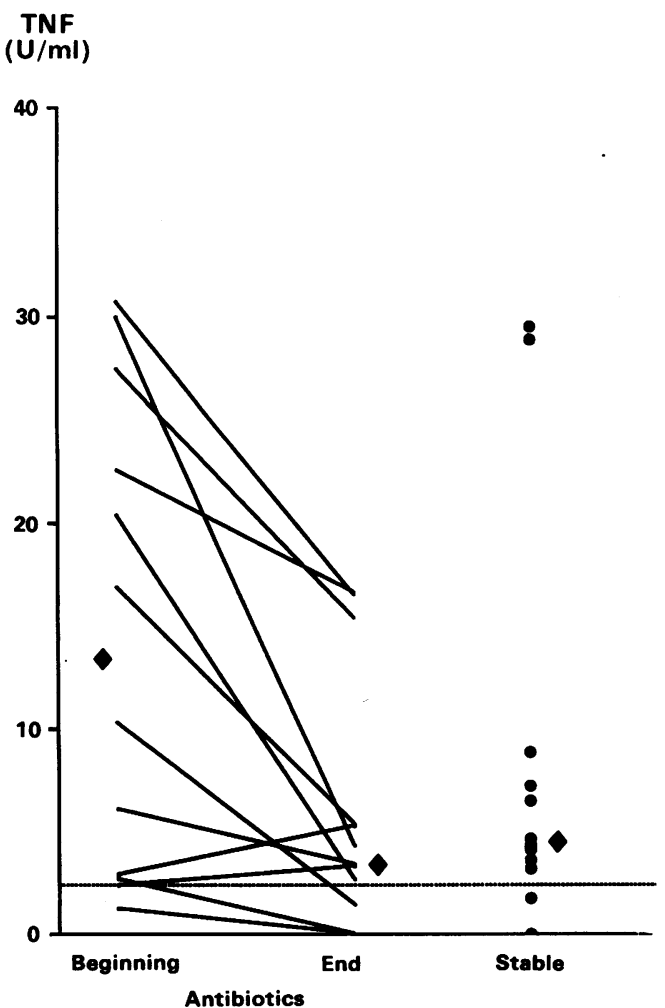

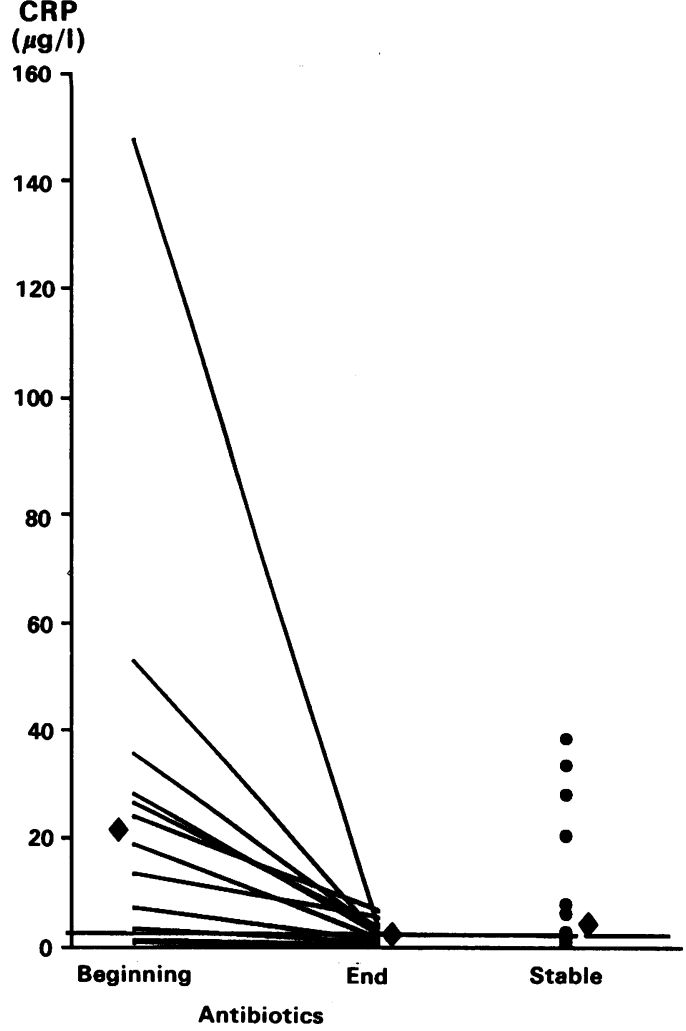

neutrophil activation and the secretion of acute phase proteins, such as $\mathrm{C}$ reactive protein. ${ }^{16}{ }^{17} \mathrm{~A}$ previous study found no significant difference in plasma tumour necrosis factor concentrations between 22 untreated patients with cystic fibrosis and pulmonary infection and six patients who had received antibiotic treatment. The difference between these findings and our own, in which antipseudomonal antibiotic treatment reduced plasma tumour necrosis factor concentrations, is likely to be due to the

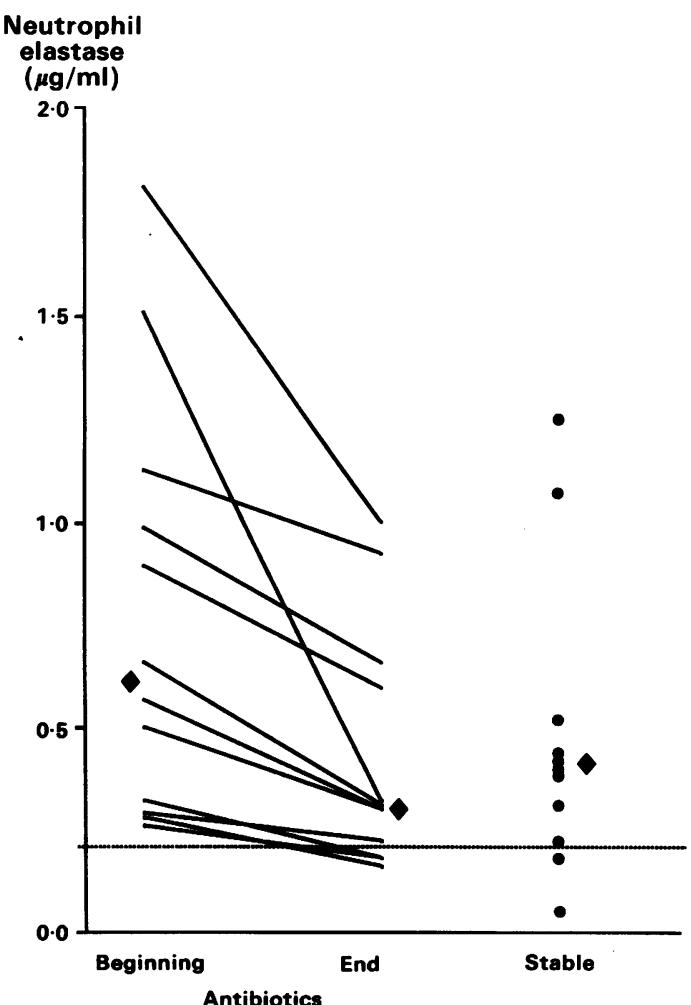


wide range of tumour necrosis factor concentrations in cystic fibrosis and the consequent problems of comparing two unrelated groups of patients. Our finding that the inflammatory response is continuous in many patients with chronic $P$ aeruginosa infection of the lung questions the validity of current patterns of intermittent antibiotic treatment and the use of clinical criteria for deciding when to start treatment. They also suggest that we should look at other treatments, such as antiinflammatory agents, to explore their potential for reducing lung destruction in cystic fibrosis. ${ }^{2223}$

A substantial increase in tumour necrosis factor occurred in most patients with cystic fibrosis and chronic $P$ aeruginosa lung infection. There was a clear relation to other inflammatory markers, indicating that the secretion of tumour necrosis factor in such patients is related to the maintenance of the inflammatory response and may thereby enhance lung destruction.

This work was supported by grants to DJS by Delta Biotechnology Ltd and Eli Lilly Ltd. JSE, SMC, SMW, and RJR were supported by the Cystic Fibrosis Research Trust. We thank Dr A Meager, National Institute for Biological Standards, for the interim tumour necrosis factor standard and monoclonal antibody to tumour necrosis factor.

1 Hesse DG, Tracey KJ, Fong Y, et al. Cytokine appearance in human endotoxemia and primate bacteremia. Surg Gynecol Obstet 1988;166:147-53.

2 Michie HR, Manogue KR, Spriggs DR, et al. Detection of circulating tumor necrosis factor after endotoxin administration. N Engl J Med 1988;318:1481-6.

3 Beutler B, Milsark IW, Cerami A. Passive immunisation against cachectin/tumor necrosis factor protects mice from lethal effects of endotoxin. Science 1985;229:869-71

4 Tracey KJ, Fong Y, Hesse DG, et al. Anti-cachectin/TNF monoclonal antibodies prevent septic shock during lethal bateremia. Nature 1987;330:662-4.

5 Waage A, Halstensen A, Espevik T. Association between tumour necrosis factor in serum and fatal outcome in
patients with meningococcal disease. Lancet 1987;i:355-7. 6 Waage A, Brandtzaeg P, Halstensen A, Kierulf P, Espevik T
The complex pattern of cytokines in serum from patients with meningococcal septic shock. J Exp Med 1989; 169:333-8.

7 Grau GE, Taylor TE, Molyneux ME, et al. Tumor necrosis factor and disease severity in children with falciparum malaria. N Engl J Med 1989;320:1586-91.

8 Scuderi P, Sterling KE, Lam KS, et al. Raised serum levels of tumour necrosis factor in parasitic infections. Lancet 1986;ii:1364-5.

9 Pier GB. Pulmonary disease associated with Pseudomonas aeruginosa in cystic fibrosis: current status of the host bacterium interaction. $J$ Infect Dis 1985;151:575-80.

10 Bruce MC, Poncz L, Klinger JD, Stearn RC, Tomashefski JF, Dearborn DG. Biochemical and pathological evidence of the proteolytic destruction of lung connective tissue in cystic fibrosis. Am Rev Respir Dis 1985;132:529-35.

11 Suter S, Schaad UB, Roux-Lombard P, Girardin E, Grau G, Dayer J-M. Relation between tumor necrosis factor-alpha and granulocyte elastase- $x_{1}$ proteinase inhibitor complexes in the plasma of patients with cystic fibrosis. Am Rev Respir Dis 1989;140:1640-4.

12 Salonen EM. A rapid and sensitive solid phase enzyme immuno-assay for C-reactive protein. $J$ Immunol Methods 1982;48:45-50.

13 Rocker GM, Wiseman MS, Pearson D, Shale DJ. Diagnostic criteria for adult respiratory distress syndrome: time for reappraisal. Lancet 1989;i:120-3.

14 Campbell MJ, Gardner MJ. Calculating confidence intervals for some non-parametric analyses. $\mathrm{Br} \mathrm{Med} J$ 1988;296:1454-6.

15 Berkow RL, Wang D, Larrick JW, Dodson RW, Howard TH. Enhancement of neutrophil superoxide production by preincubation with recombinant human tumour necrosis factor. J Immunol 1987;139:3783-91

16 Billingham MEJ. Cytokines as inflammatory mediators. $\mathrm{Br}$ Med Bull 1987;43:350-70.

17 Tracey KJ, Vlassara H, Cerami A. Cachectin/tumour necrosis factor. Lancet 1989;i:1 122-5.

18 Høiby N, Döring G, Schiøtz PO. The role of immune complexes in the pathogenesis of bacterial infections. Ann Rev Microbiol 1986;40:29-53.

19 Crozier DN. Cystic fibrosis. A not so fatal disease. Pediat Clin of North Am 1974;21:935-49.

20) Glass S, Hayward C, Govan JRW. Serum C-reactive protein in assessment of pulmonary exacerbations and antimicrobial therapy in cystic fibrosis. $J$ Pediat 1988;113:76-9.

21 Hollsing AE, Lantz B, Bergstrom K, Malmborg AS, Strandvik B. Granulocyte elastase- $x_{1}$ antiproteinase complex in cystic fibrosis: sensitive plasma assay for monitoring pulmonary infections. J Pediatr 1987;111:206-11.

22 Auberbach HS, Williams M, Kirk-Patrick JA, Colton HR Alternative day prednisolone reduces mortality and improves pulmonary function in cystic fibrosis. Lancet 1985;ii:686-8.

23 Konstan MW, Vargo KM, Davis PB. Ibuprofen attenuates the inflammatory response to Pseudomonas aeruginosa in a rat model of chronic pulmonary infection. Am Rev Respir Dis 1990;141:186-92. 